\title{
An informed objection to mammography screening
}

\author{
Mammography Screening: Truth, Lies \\ and Controversy \\ Peter C. Gøtzsche \\ Radcliffe Publishing; 2012
}

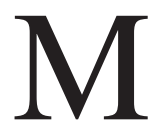

ammography Screening reads a bit like a whodunit novel, appealing most to those who revel in a good political or crime page-turner, where ethical lines are drawn and "people tend to control and distort the information to serve their own interests." The interests include those of journalists, politicians, bureaucrats, researchers, physicians and breast cancer advocates. This latter group will find Peter C. Gøtzsche's revelations particularly troubling because as foot soldiers in the war on breast cancer, many of these advocates enlisted because their lives, or the lives of their sisters, mothers and daughters were saved by breast cancer screening. Gøtzsche might encourage some of these to become conscientious objectors.

Gøtzsche, the physician who started and directs the Nordic Cochrane Centre in Copenhagen, has been publishing reviews on mammography screening programs for more than a decade. His specialty, broadly speaking, is bias in clinical research. For a scholar of bias, mammography is a perpetual playroom.

Gøtzsche has followed, and participated in the ups, the downs and the controversies around the most studied, most promoted and probably most viscerally defended screening program on the planet. The book is filled with detailed pictures of some of dishonesty's more nefarious cousins including scientific fraud, bald-faced corruption and squidgy medical opinion posing as fact, as well as many of humanity's more pathetic failings that arise when deeply entrenched interests strive to defend what is an increasingly

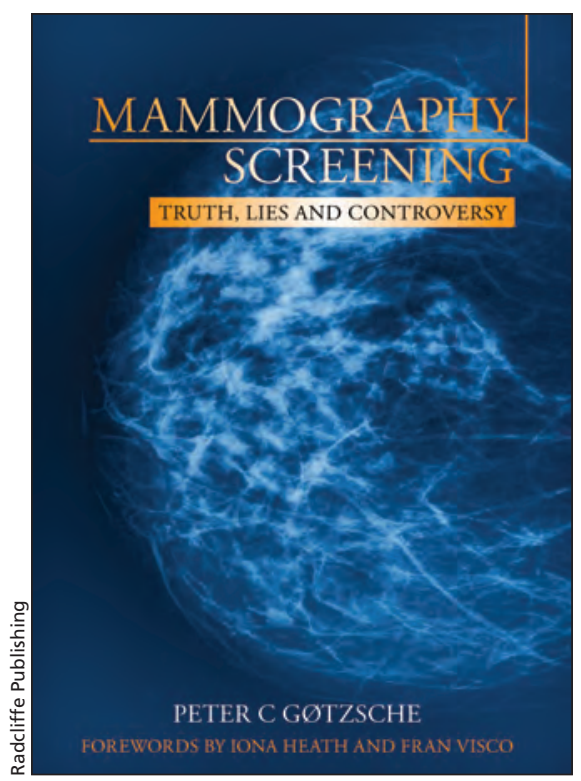

indefensible endeavor. On almost every one of these 388 pages, Gøtzsche shows a single-minded commitment bordering on fanaticism - to rooting out exaggeration, finding the truth and exposing dishonesty.

Much of the messaging on mammography asserts that it can reduce the rates of breast cancer deaths or can extend survival time, quoting big numbers such as $30 \%$ or $40 \%$ reductions. Gøtzsche argues that things such as "survival time" are very misleading and what we really need to know is if women live longer because they undergo mammography. He shows repeatedly that if mammography saves lives, those savings are tiny and come at a huge cost. He quotes Nancy Newman, a lawyer with the National Conference of Women's Bar Associations who wrote that "the lack of a discernible effect on overall mortality means that if mammography prolongs life in some women it may lead to overtreatment or even shortening of life in just as many."

This book will make many people uncomfortable, not only because it deflates some very cherished beliefs, but because it catalogues so many varieties of dishonourable conduct which could apply to many other highly cherished, but perhaps scientifically unsound medical interventions. Gøtzsche tends to shower us with tons of detail and he likes naming names, telling us who said, wrote or asserted what, who cherrypicked the data, and who was out there flinging ad hominem attacks because that's the only ammo they had left against Gøtzsche and his colleagues.

Last year, it was the very same Gøtzsche who threw down the gauntlet in the pages of the CMAJ, saying that "the best method we have to reduce the risk of breast cancer is to stop the screening program." The question he left us, (remember this was in a Canadian medical journal) was: "Which country was going to be the first to stop mammography screening?"'

Gøtzsche has revealed that a scandal of monstrous proportions has been unleashed on the female population of the world where, "hundreds of millions of women have been seduced into attending screening without knowing it could harm them." His book will most certainly start undoing that harm.

\section{Alan Cassels MPA}

Drug Policy Researcher

University of Victoria

Victoria, BC

Alan Cassels is the author of Seeking Sickness: Medical Screening and the Misguided Hunt for Disease (Greystone, 2012) and coauthor of Selling Sickness, with Ray Moynihan. In the last five years he has interviewed Peter Gøtzsche on several occasions, at meetings of the Cochrane Collaboration in Germany, France and Spain.

\section{Reference}

1. Gøtzsche PC. Time to stop mammography screening? CMAJ 2011;183:1957-8. Available: www.cmaj .ca/content/183/17/1957 (accessed 2012 July 9). 